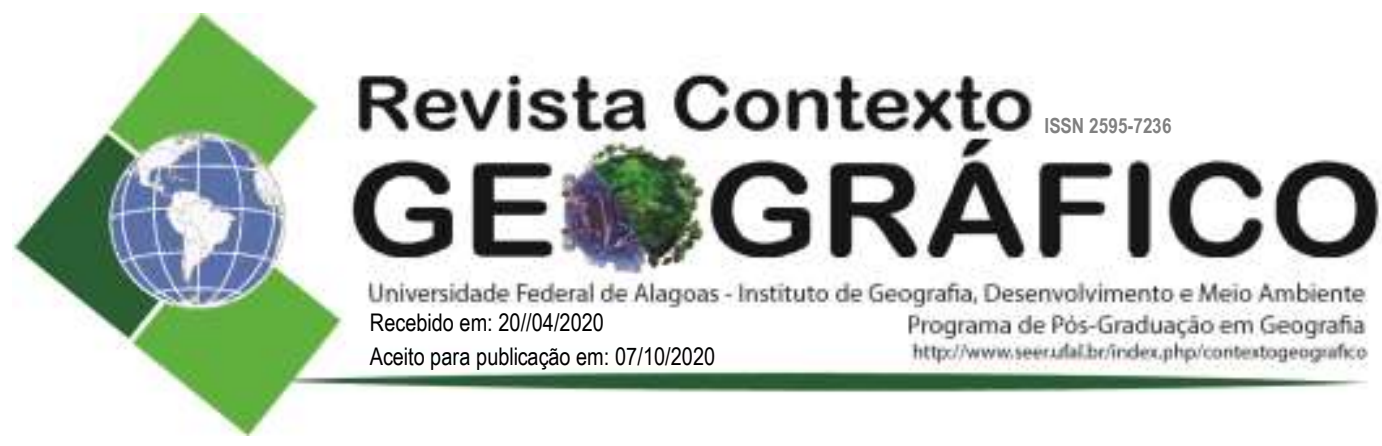

\title{
A FEIRA LIVRE DE GUARANÉSIA-MG SOB A ÓTICA DO CIRCUITO INFERIOR DA ECONOMIA
}

\author{
Thiago Silva Forte \\ Universidade Federal de Alfenas (UNIFAL), Minas Gerais, Brasil \\ thiago.guitarg3@gmail.com \\ Renata Vieira de Melo \\ Universidade Federal de Alfenas (UNIFAL), Minas Gerais, Brasil \\ renata.vieirademelo78@gmail.com
}

\begin{abstract}
RESUMO - O presente artigo busca compreender a dinâmica econômica da feira livre do município de Guaranésia-MG, que é uma das manifestações no Espaço geográfico do circuito inferior da economia elaborado por Milton Santos, objetiva-se com isso demonstrar sucintamente como o circuito inferior da economia urbana ocorre nesse município e alguns de seus elementos como a importância da feira livre para a renda familiar dos munícipes, bem como compreender as nuances de sua configuração no espaço geográfico. Para se alcançar os resultados foram feitos levantamentos e revisões bibliográficas, trabalho de campo, entrevistas e coleta de dados. A partir dos dados obtidos é possível afirmar que a feira gera trabalho e renda no campo, assim como dinamiza a economia local e proporciona a soberania e segurança alimentar para a população urbana, além de ser espaço privilegiado de organização e participação social.
\end{abstract}

Palavras-chave: Urbanização; Trabalho; Espaço geográfico.

\section{THE FREE FAIR OF GUARANÉSIA-MG UNDER THE OPTICS OF THE INFERIOR CIRCUIT OF THE ECONOMY}

\begin{abstract}
The present article searchs to understand the economic dynamics of the free fair of the city of Guaranésia-MG, that is one of the manifestations in the geographic Space of the inferior circuit of the economy elaborated for Milton Santos, objective with this to demonstrate sucintamente as the inferior circuit of the urban economy occurs in this city and some of its elements as the importance of the free fair for the familiar income of the townspeople, as well as understanding nuances of its configuration in the geographic space. To reach the results surveys and bibliographical revisions had been made, work of field, interviews and collect of data. From the gotten data it is possible to affirm that the fair generates work and income in the field, as well as dinamiza the local economy and provides to the sovereignty and alimentary security for the urban population, beyond being privileged space of organization and social participation.
\end{abstract}

Keywords: Urbanization; Work; Geographic space.

\section{INTRODUÇÃO}

O Espaço geográfico enquanto categoria de análise da Geografia foi desde a origem da ciência geográfica objeto de estudo e de diversas análises e explicações com relação a sua organização, dinâmica e transformações sofridas ao longo do tempo.

Enquanto elemento da sociedade pode-se afirmar que o Espaço geográfico é constantemente produzido e transformado por meio de atividades sociais nas esferas econômicas, culturais, políticas, carregando consigo elementos do passado e do presente, devido a isso, compreendê-lo 
é também uma forma de entender o próprio ser humano e a estrutura das sociedades.

É evidente que a produção do espaço geográfico não é uniforme, ela se dá através de formas multifacetadas devido à complexidade das relações humanas com o mesmo, desta maneira as configurações espaciais se diversificam de acordo com a escala, ou fenômeno observado.

A cidade/urbano de modo geral se torna um elemento de análise, pois nela ocorre a produção e a diferenciação dos espaços que atendem os diversos interesses sociais. Nesta perspectiva, a análise sobre o Espaço urbano foi objeto de estudo do geógrafo Milton Santos que em suas obras dedicou-se a compreender e analisar as cidades dos países denominados de subdesenvolvidos a partir de suas características e fatores de diferenciação, sobretudo em relação ao papel de destaque de atividades como os pequenos comércios e a prestação de serviços inseridos na dinâmica das cidades. Nesta perspectiva voltada ao melhor entendimento da dinâmica urbana, Milton Santos cria a teoria dos circuitos da economia nomeados por ele de circuito inferior $(\mathrm{CI})$ e o superior (CS).

O circuito superior (CS) vem com grande carga de alta tecnologia e modernização e sua referência é nacional e internacional, caracterizado pela fluidez e flexibilidade. Já o circuito inferior atua em escala menor atingindo as camadas mais pobres da população, contudo "é bem enraizado mantém relações privilegiadas com sua região. Cada circuito forma um sistema, isto é, um subsistema do sistema urbano" (SANTOS, 1978).

Considerando a importância de se estudar a teoria dos circuitos da economia, formulada por Milton Santos no final da década de 1960, e tendo como análise empírica o município de Guaranésia situado no sul do estado de Minas Gerais, todo o esforço analítico e teórico foi destinado a compreender a dinâmica econômica da feira livre do município, que é uma das manifestações, no Espaço, do circuito inferior da economia, objetiva-se com isso demonstrar sucintamente como o circuito inferior da economia urbana ocorre nesse município e quais são alguns de seus elementos.

A metodologia empregada é baseada principalmente em levantamentos e revisões bibliográficas, pesquisa de campo, entrevistas, conversação e observação como instrumentos de coleta de dados, no intuito de identificar os agentes sociais envolvidos e as atividades comerciais que fazem parte desse circuito e que estão presentes nessa e na maioria das cidades.

O feirante foi o centro da pesquisa, realizada através de questionário que abordasse a importância da feira para a renda familiar, os tipos de produtos, as técnicas utilizadas para a produção, incentivos governamentais concebidos, assim como traçar o perfil desse feirante e mapear a logística de escoamento dessas mercadorias. Sobre o espaço da feira, buscou-se analisar a infraestrutura e vantangens e desvantagens de participar deste ambiente.

\section{CARACTERIZAÇÃO DA ÁREA DE ESTUDO}

O município de Guaranésia se localiza no sul do estado de Minas Gerais estando inserido na microrregião de São Sebastião do Paraíso. A população estimada em 2018 pelo IBGE foi de 19.025 habitantes. O município conta com uma área em torno de $294 \mathrm{~km}^{2}$ incluídos em sua extensão territorial, além da sede municipal, mais um distrito, Santa Cruz da Prata, e mais oito comunidades, composta por bairros rurais.

A atividade econômica que mais se destaca no município é a agricultura com cultivos que se baseiam na produção do café, da cana-de-açúcar, milho, arroz, feijão e laranja sendo que o café e a cana-de-açúcar são os produtos de maior peso no agronegócio do município, no entanto, nos últimos anos a atividade industrial do município demonstra franca expansão sendo o setor mais notável a indústria têxtil, que vai de prestação de serviços, como bordados e estampagem às grandes indústrias de fiação. O comércio local na última década se desenvolveu aceleradamente com o crescimento da chamada "parte alta da cidade" (bairros geograficamente mais altos que a 
região central), o comércio migra-se então principalmente para um bairro nomeado "Bom Jesus", concentrando-se em uma rua conhecida como a "rua do comércio", onde é possível encontrar praças de alimentações, restaurantes, confecções e é neste recorte espacial que está localizada a feira livre, objeto de estudo deste trabalho.

Figura 1. Mapa da área de estudos. Fonte: IBGE 2019

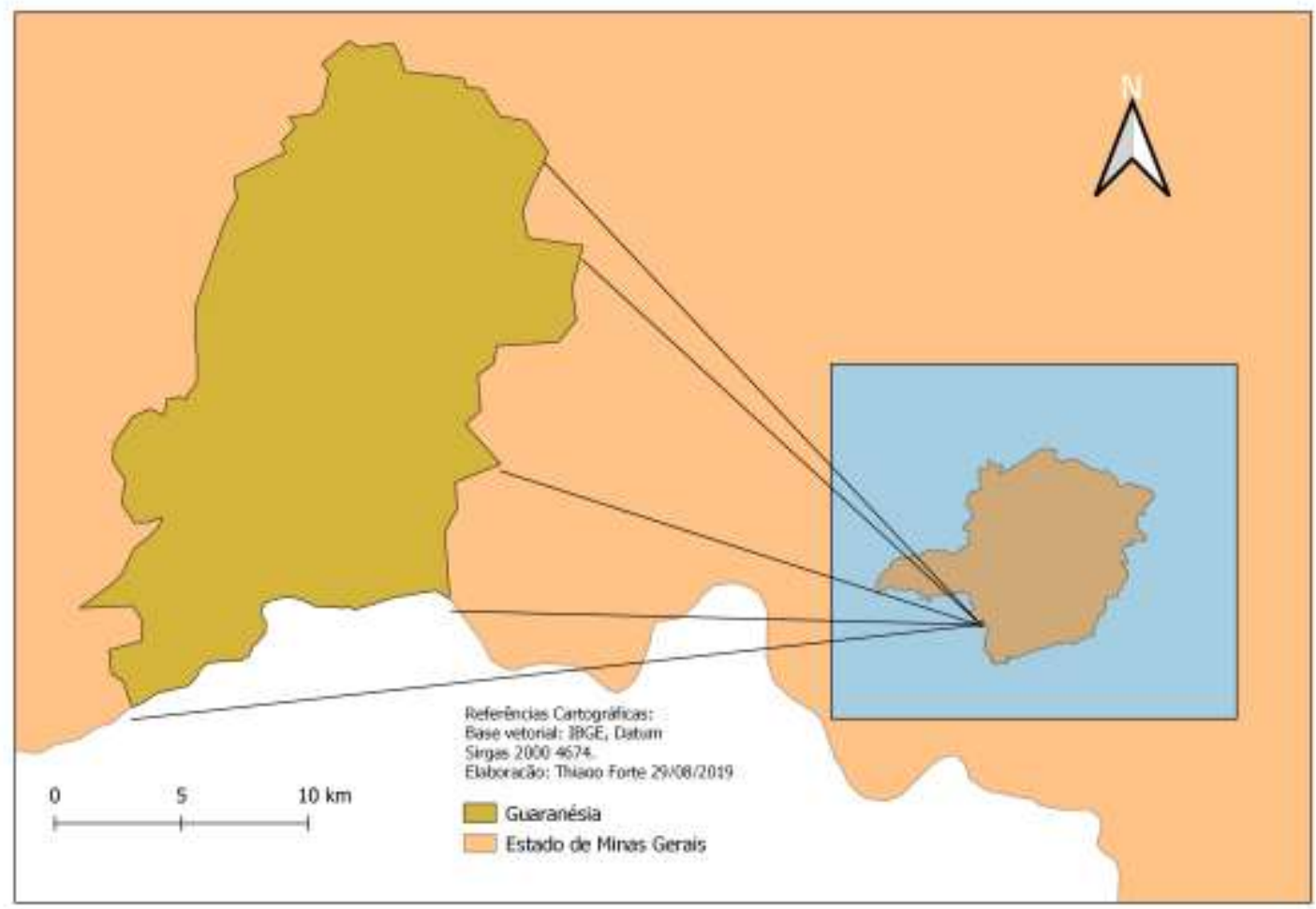

Org. Autores (2019).

Segundo dados do Censo Agropecuário de 2006, 84,4\% do total dos estabelecimentos agropecuários brasileiros pertencem a grupos familiares. De acordo com o estudo a agricultura familiar constitui a base econômica de $90 \%$ dos municípios brasileiros com até 20 mil habitantes, caso que se relaciona ao município de Guaranésia que acompanha a média nacional.

Do montante da população do município vivem no campo aproximadamente 1876 pessoas sendo cerca de 250 consideradas nos atributos da lei agricultores familiares, que cultivam principalmente café, soja, milho, cana de açúcar, legumes, frutas e verduras.

Através de análises dos dados obtidos junto a EMATER, dos 250 agricultores familiares do município apenas 10 agricultores cultivam suas produções sem o uso de agrotóxicos, ou seja, $96 \%$ dos agricultores familiares do município em questão utilizam agrotóxicos comprados principalmente na Cooxupé (maior cooperativa de café do mundo) e em lojas de implementos e insumos agrícolas.

É de fundamental importância destacar que os 10 agricultores que não se utilizam de agrotóxicos em suas produções estão vinculados ao Programa Nacional de Alimentação Escolar (PNAE) fornecendo alimentos às escolas do município assim como abastecem a feira livre, suas principais produções contam com legumes, verduras e frutas. De acordo com os dados obtidos junto a EMATER o fornecimento destes alimentos as escolas gerou uma renda de aproximadamente 129.723,00 R \$ no último ano, cabe salientar que a não utilização de agrotóxicos é condição básica dentre os requisitos para ser contemplado por esse programa governamental. 
Além da oferta de produtos para alimentação escolar outro meio de comercialização de produtos da agricultura familiar no município é a feira livre da agricultura familiar, que têm sido ao longo dos anos fomentada e fortalecida pela Emater em conjunto com a Prefeitura Municipal, conferindo então um importante canal de comercialização.

Figura 2. Feira livre de Guaranésia-MG. Fonte: Própria.

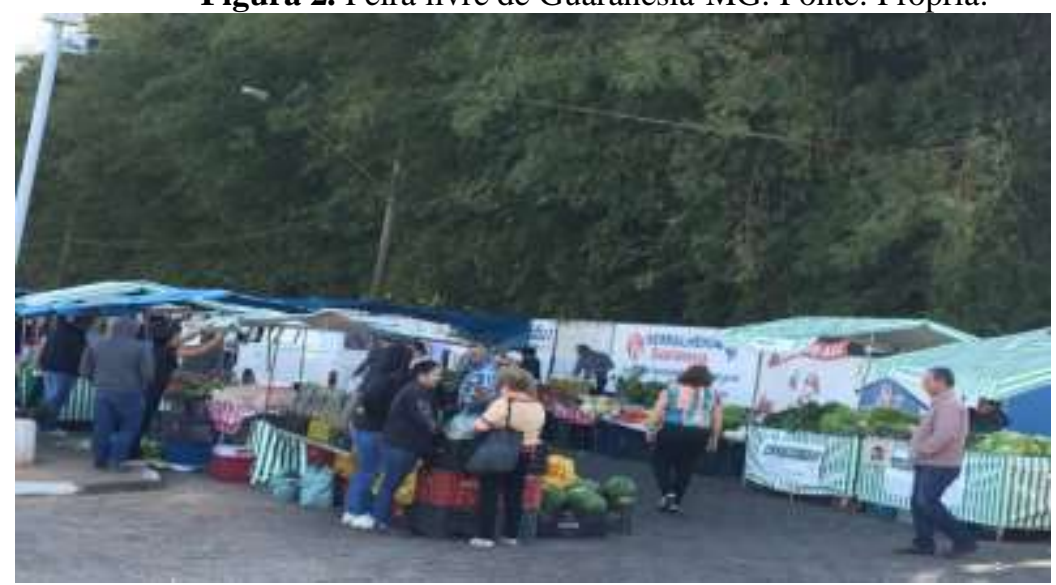

A feira livre da agricultura familiar no município de Guaranésia-Mg é uma iniciativa da Prefeitura Municipal juntamente com a Secretaria de Meio Ambiente e Agropecuária e o Departamento de Tributos e faz parte do programa "Aqui Tem Feira", onde alguns agricultores participantes de programas sociais (agricultura familiar, PNAE, etc.) foram contemplados com "Kits feira" contendo barracas ofertadas a eles, em regime de comodato. Este projeto conta ainda com o apoio da Emater-Mg, que auxilia na instrução de boas práticas no manejo de produtos agropecuários e como levar esse produto até o consumidor final.

Figura 3. Barraca oferecida pela EMATER-MG. Fonte: Própria.

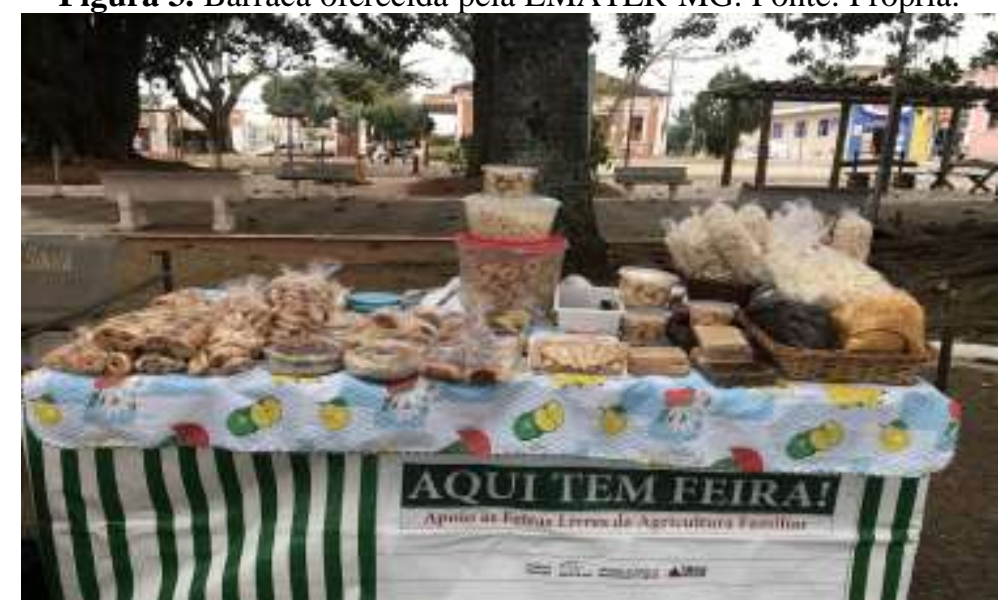

Dos produtos oferecidos pela feira livre da agricultura familiar são ofertados principalmente verduras, frutas, legumes, quitutes, pastéis, doces e artesanatos. 


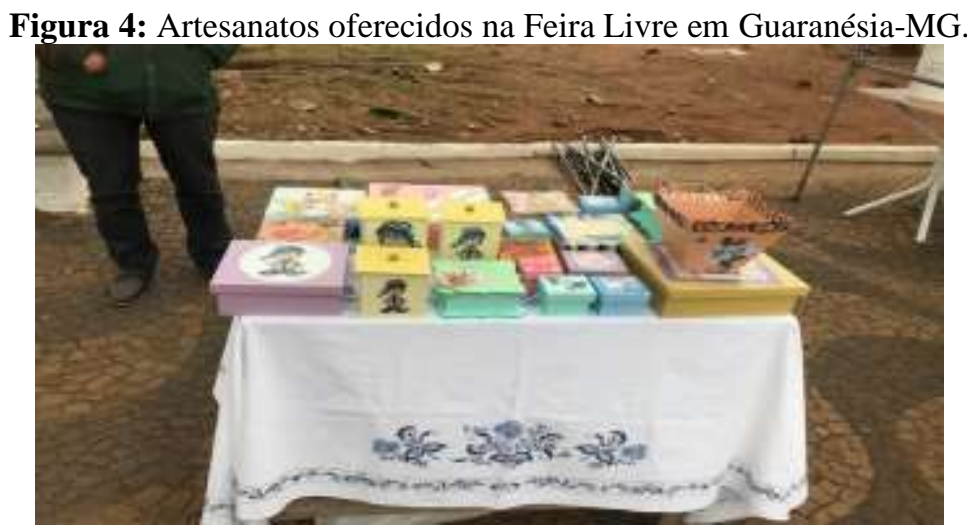

Fonte: Acervo dos autores

A feira livre da agricultura familiar é composta por agricultores familiares residentes no município de Guaranésia-MG, sendo essa condição (ser residente) determinante para ser contemplado com o programa. Os produtos são plantados em sítios e chácaras próprios ou arrendados localizados na área rural, distrito e bairros rurais do município. É de fundamental importância salientar que a partir dos dados obtidos $80 \%$ dos feirantes são residentes do município, sendo o restante de cidades vizinhas como Guaxupé - MG, Juruaia - MG e São Jose do Rio Pardo - SP, portanto não são contemplados com os benefícios do programa 'feira da agricultura familiar' havendo a necessidade de pagamento de um alvará no valor de duzentos e onze reais ao ano para regularizarem a exposição de seus produtos na feira.

$\mathrm{O}$ funcionamento da feira acontece ao menos duas vezes por semana preferencialmente aos domingos e na quinta feira, dias em que população local e da região podem adquirir na feira produtos alimentícios (frutas, verduras, legumes, doces, biscoitos, bolos) além de artesanato (caixas decorativas, bordados, trabalhos com barbantes, linhas e com tecido).

Figura 5. Produtos oferecidos na feira livre de Guaranésia-MG.

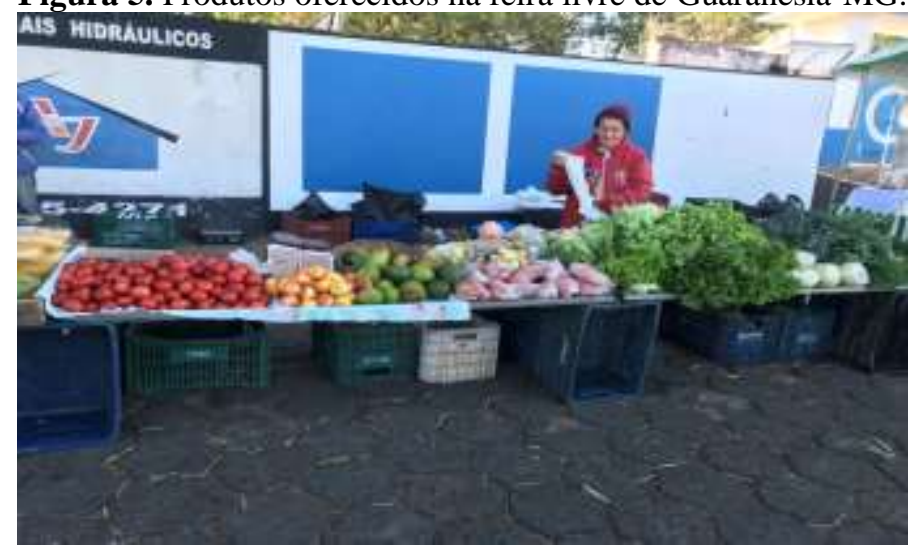

Fonte: Acervo dos autores

Em cada barraca há um tipo de produto específico à venda, sendo que a maioria desses produtos oferecidos ao consumidor pelo próprio produtor. Esse tipo de comércio é típico de uma economia espacial diversificada e com seus atributos específicos. Os produtos oferecidos pelos agricultores familiares contemplados pelo programa municipal são orgânicos, portanto, livre de agrotóxicos.

Em entrevista com os representantes do Governo Municipal, os mesmos afirmam esta é uma ação muito positiva, pois dá o primeiro passo na valorização dos pequenos agricultores, provocando neles o espírito cooperativista e também fomentando a agregação de valor aos produtos comercializados. 


\section{O CIRCUITO INFERIOR DA ECONOMIA}

Os circuitos da economia teorizados por Milton Santos são elementos indispensáveis para compreensão da economia urbana em qualquer cidade e, em se tratando do nosso objeto de estudo, o enfoque principal é no circuito inferior (CI) presente na economia das pequenas cidades.

Para Santos (2004), as cidades dos países em desenvolvimento não funcionam como um aparelho maciço ou como um bloco; dentro do sistema urbano, pode-se reconhecer a existência de dois subsistemas mesmo dependentes de outros sistemas de níveis superiores, dois circuitos da economia, o "circuito superior" e o "circuito inferior".

De acordo com Santos (1979) "o circuito inferior compreende as atividades de fabricação tradicionais, como o artesanato, assim como os transportes tradicionais e a prestação de serviços", ele é constituído por formas de fabricação não- "capital intensivo", pelos serviços não modernos fornecidos "a varejo" e pelo comércio não moderno de pequena dimensão. O circuito superior é constituído pelas atividades comerciais, indústria de exportação e pelos serviços modernos, pelos bancos, pelo comércio atacadista e pelas atividades ligadas ao transporte.

O Circuito superior (CS) é o resultado direto da modernização tecnológica com grande destaque para o desenvolvimento de atividades modernas atendendo aos interesses do grande capital e de parte da população mais abastada. Já no circuito inferior os indivíduos beneficiam-se parcialmente das atividades ligadas a essa modernização. É nesse sentido que o modo de produção capitalista produz regiões que dependem de outras e subsistemas que são subordinados a outros.

Nota-se que paralelamente a esse setor formal que Santos (2004) denomina como sendo o circuito superior, ocorre um setor inferior, que se caracteriza por fazer parte da economia e, portanto está conectado com o setor superior, mas que não utiliza de elementos inseridos no cotidiano do comércio formal, como ocorre com as linhas de crédito e financiamento ou os espaços físicos definidos e consolidados e a propriedade privada.

Santos (2004) considera que o circuito inferior constitui também uma estrutura de abrigo para os citadinos, antigos ou novos, desprovidos de capital e de qualificação profissional, a população ativa que "dá um jeitinho de viver", onde o trabalho é o fator essencial no circuito inferior, quando no circuito superior é o capital, gerando um esforço para subsistir e adaptações às condições impostas pelo sistema capitalista.

Esse setor inferior pode ser visto e espacializado na feira livre do município de Guaranésia-MG, que se mostra como uma expressão cultural e econômica da região e que demonstra aspectos da economia informal local, abordados neste estudo.

Enquanto no circuito superior a organização do trabalho é burocrática, no inferior e, no caso das feiras livres, ela se dá de forma não oficial, a organização do trabalho no circuito inferior se dá pela característica não formal e não oficial. Segundo Porto (2005), nas feiras livres, os vendedores organizam-se desprovidos de fiscalização, pois, dentre outras características, não há um controle rígido de quem pode ou não, ali, comercializar seus produtos.

De acordo com observações feitas durante a pesquisa de campo o principal tipo de suporte utilizado para sustentar suas mercadorias são barracas e esteiras, sendo as barracas dos agricultores familiares fruto da doação concedida pela EMATER enquanto a esteira construída de modo simples pelos próprios feirantes que não participam do programa sob essas bancadas ocorre à exposição dos produtos a serem comercializados.

Em relação às medidas sanitárias foi possível constatar que muitos feirantes adotam uma postura despreocupada trabalhando concomitantemente no manuseio de alimentos e no recebimento em dinheiro, assim como comercializam seus produtos sem selo de validade e sem embalagens conservantes o que evidencia a negligência por parte dos órgãos públicos 
municipais que não fazem fiscalização sanitária.

Outra característica inerente do circuito inferior é a utilização de meios de transporte mais "simples" na condução dos produtos da sua área original até o local da feira, a partir das observações e das análises dos dados coletados podemos afirmar que a condução dos produtos da área de produção até a área de comercialização se realiza através de carros, caminhonetes e tratores, cabe ressaltar que o transporte dos produtos fica a cargo dos próprios feirantes, não havendo qualquer auxílio e fiscalização da prefeitura municipal.

Figura 6. Transportes utilizados para condução dos produtos à feira

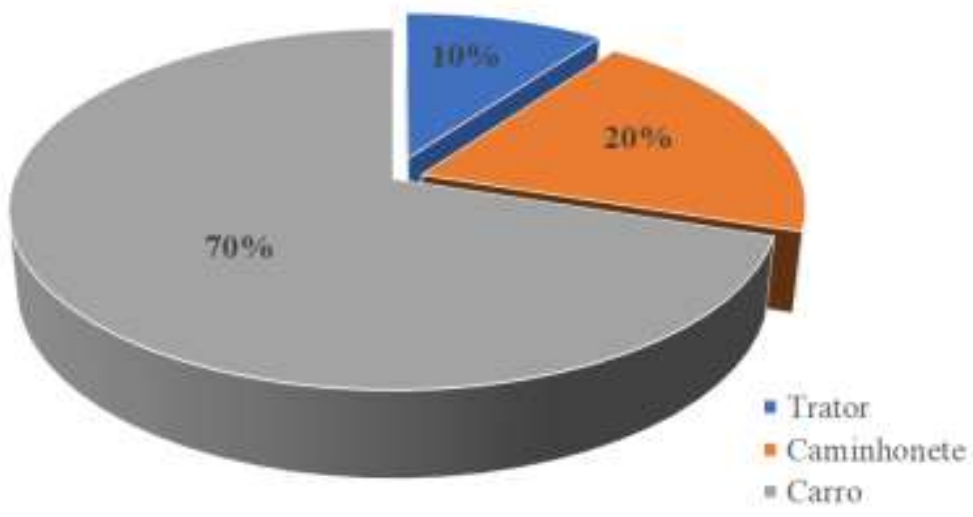

Fonte: Pesquisa de campo na feira livre de Guaranésia-MG, Julho-2019

Neste aspecto desponta um problema: a inexistência de trans $\neg$ porte gratuito para os feirantes, não fazendo parte das ações, nem sistemáticas nem pontuais, do poder público para favorecer a feira.

A ausência de transporte gratuito é um dos principais problemas enfrentados pelos agricultores feiᄀrantes, pois além do deslocamento deles próprios, tem o peso dos alimentos, espaço ocupado pelas barracas/esteiras o que requer que várias viagens sejam feitas havendo um gasto maior com combustível/transporte.

Figura 7. Imagens dos meios de transporte utilizados na feira.

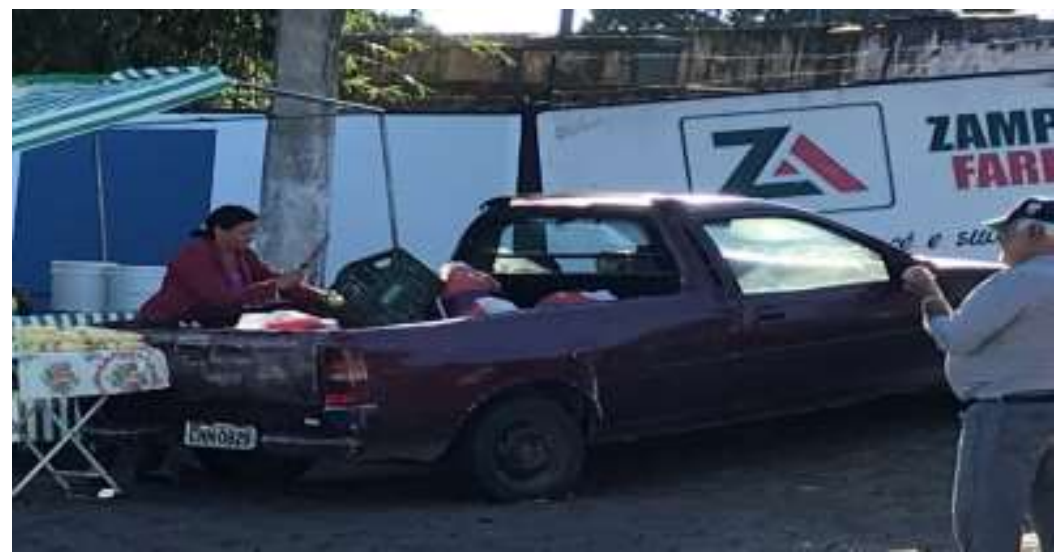

Fonte: Acervo dos autores 
Em relação ao valor empregado para funcionamento da atividade comercial, manutenção, pagamentos de funcionários, compra de mercadorias e transporte foi possível constatar que há um valor reduzido de capital empregado o que confirma a feira livre como atividade do circuito inferior da economia, pois, segundo Santos (1979), no CS o valor de capital empregado para o funcionamento da atividade comercial é importante, nesse caso, destina-se valores altos para seu funcionamento. No CI esse valor é reduzido.

Figura 8. Investimento de capital anual.

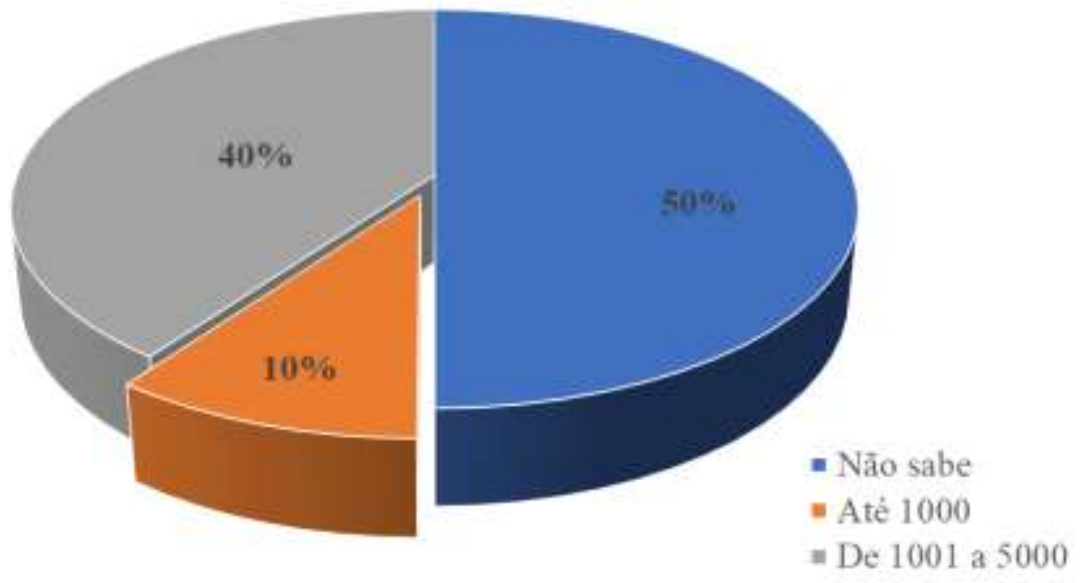

Fonte: Pesquisa de campo na feira livre de Guaranésia-MG, Junho-2019.

O circuito inferior da economia caracteriza-se por apresentar uma grande oferta de empregos se totalizada a quantidade de estabelecimentos ou unidades de produção, porém, nesse circuito, cada indústria ou ponto de venda oferece um número reduzido de empregos, embora seja difícil defini-los, pois compreendem tanto o trabalho mal remunerado como o trabalho temporário e instável, Porto (2005). A organização do trabalho no circuito inferior se dá pela característica não formal e não oficial.

Santos (1976) afirma que a utilização de membros da família nas atividades comerciais substitui o trabalho assalariado, que obrigaria o comerciante a pagar encargos sociais e impostos, o que poderia inviabilizar uma atividade onde a demanda é flutuante

Figura 9. Relações de Trabalho

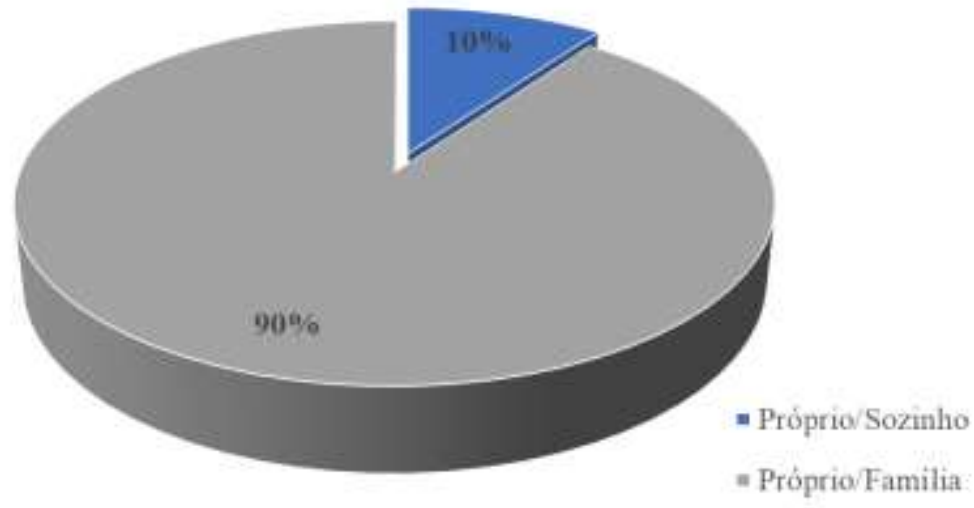

Fonte: Pesquisa de campo na feira livre do município de Guaranésia-MG, julho-2019 
Com relação ao estoque de produtos como podemos ver no gráfico 3 aos estoques são baixos, o que configura mais uma vez uma característica marcante do circuito inferior da economia, este fato está diretamente ligada à falta de infraestrutura adequada para estocagem dos produtos, assim como ao fator de muitos dos produtos ofertados são perecíveis o que impossibilita seu armazenamento por longos períodos de tempo, ligado a isso também podemos explicar a variação no preço dos produtos, que se tornam cada vez mais baratos quanto mais se aproxima do horário de término da feira, ou seja, os preços não são fixos e podem variar ao longo da exposição da feira, sendo muitas vezes o lucro deixado de lado com o intuito de esgotar os produtos ali ofertados.

Figura 10. Estoque de mercadorias pelos feirantes.

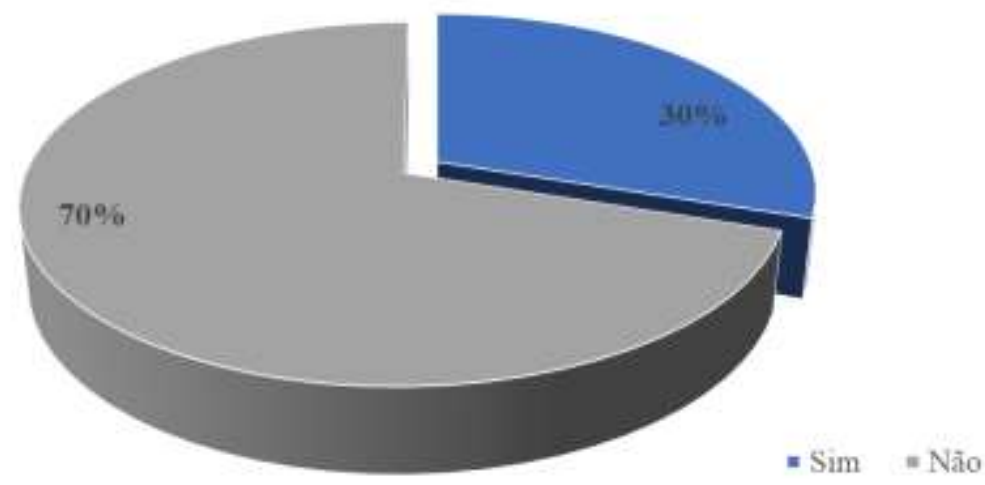

Fonte: Pesquisa de campo na feira livre em Guaranésia-MG, junho-2019

Em relação às atividades desempenhadas fora da feira, a partir da análise dos dados obtidos os feirantes entrevistados afirmaram trabalhar exclusivamente na feira sendo esta a atividade geradora da renda familiar.

\section{CONSIDERAÇÕES FINAIS}

A feira livre é uma das formas mais antigas de comercialização de produtos agrícolas desempenhando a função econômica a partir da comercialização direta entre agricultores e consumidores. Além de compor a renda familiar das famílias que vivem no campo, as feiras proporcionam um espaço agradável para os consumidores dos centros urbanos, que buscam cada vez mais qualidade de vida por meio de uma alimentação saudável.

As feiras livres são um importante espaço de comercialização dos produtos da agricultura familiar, como também espaço de socialização, identidade regional, cultural, de articulação política, sindical, assim como é local de reprodução da identidade e da cultura de um território. Um espaço que representa uma resistência ao mundo globalizado, mercantil e industrializado, enfim, um lugar onde convivem de forma democrática e harmoniosa todas as classes sociais. Nas feiras há movimentação de produtos, pessoas, informações e cultura, enriquecendo a dinâmica urbana e compondo a paisagem local.

A partir dos dados obtidos com nosso trabalho é possível afirmar que a feira gera trabalho e renda no campo, assim como dinamiza a economia local e proporciona a soberania e segurança alimentar para a população urbana, além de ser espaço privilegiado de organização e participação social.

As feiras geram capital que compõem a economia do município, produz e coloca em circulação produtos frescos que alimentam a população urbana e contribuem para a soberania alimentar. As 
feiras livres beneficiam não só aos agricultores, como também ao comércio e aos consumidores.

E como salientou Milton Santos, "sem dúvida defrontamo-nos com a nítida insuficiência dos dados estatísticos concernentes ao circuito inferior da economia urbana...", por isso necessário é que novas pesquisas a respeito sejam feitas no campo. (SANTOS, 2004)

Portanto, é de grande importância conhecer a dinâmica de funcionamento da feira-livre existente nos municípios, contribuindo com a ampliação do conhecimento acerca do espaço geográfico. Desta forma, este trabalho busca compor um campo referencial para embasamento em pesquisas futuras mais aprofundadas acerca do tema e que os resultados apresentados aqui possam subsidiar ações do poder público local e intervenções coletivas dos feirantes no sentido de fortalecer estes espaços tão importantes para a agricultura familiar e o desenvolvimento rural.

\section{REFERÊNCIAS}

INSTITUTO BRASILEIRO DE GEOGRAFIA E ESTATÍSTICA-IBGE/Cidades. Acesso em julho de 2019.

PORTO, Carlos Silveira Gil. Configuração Sócio-espacial e Inserção das Feiras Livres de Itapetinga-BA e arredores no Circuito Inferior da Economia, UFB, 2005.

SANTOS, Jânio \& SERPA, Ângelo. 2001. A produção espacial do comércio e serviços nas periferias urbanas: um estudo de caso em Salvador - in Geousp: Espaço e Tempo, n. 8 - São Paulo: USP. p. 45-65.

SANTOS, Milton. 1978. Por uma Geografia nova: Da crítica da Geografia a uma Geografia crítica. São Paulo: Hucitec.

1979. O espaço dividido: os dois circuitos da economia dos países subdesenvolvidos - Rio de Janeiro: F. Alves.

1985. Espaço e Método. São Paulo: Nobel.

SANTOS, M. O espaço dividido: os dois circuitos da economia urbana dos países subdesenvolvidos. São Paulo: Edusp, 2004. 